\title{
Correction to: Providing Patients with Critical or Life-Threatening IIInesses Access to Experimental Drug Therapy: A Guide to Clinical Trials and the US FDA Expanded Access Program
}

Marjorie A. Speers ${ }^{1}$ (D)

Published online: 4 July 2020

(c) Springer Nature Switzerland AG 2020

Correction to: Pharmaceutical Medicine (2019) 33:89-98 https://doi.org/10.1007/s40290-019-00274-3

Page 96, reference list: Reference 24, which previously read:

24. Van Norman G. Drugs, devices, and the FDA: part 1: an overview of approval processes for drugs. J Am Coll Cardiol Basic Trans Science. 2016;1:170-9.

should read:

24. Van Norman GA. Drugs, devices, and the FDA: part 1: an overview of approval processes for drugs. JACC Basic Transl Sci. 2016;1(3):170-9.
The original article can be found online at https://doi.org/10.1007/ s40290-019-00274-3.

Marjorie A. Speers

mspeers@clinicalresearchpathways.org

1 Clinical Research Pathways, 245 N Highland Ave, Suite 230, Atlanta, GA 30307, USA
Page 97, reference list: Reference 68, which previously read:

68. Norman GA. Expanding patient access to investigational drugs. Single patient investigational new drug and the "right to try". JACC:Basic Transl Sci. 2018;3(2);280-93.

should read:

68. Van Norman GA. Expanding patient access to investigational drugs: Single patient investigational new drug and the "right to try". JACC Basic Transl Sci. 2018;3(2):280-93. 